\title{
Swine flu attention turns to the tropics
}

\section{New flu strains are more likely to arise in equatorial countries, where influenza is present the year round and surveillance is poor.}

With the influenza season over in the temperate Northern Hemisphere, and just getting under way on the other side of the world, scientists are watching the $\mathrm{A}(\mathrm{H} 1 \mathrm{~N} 1)$ swine flu virus to see where it goes next and whether it will reassort with other flu viruses, or mutate, to cause more severe disease or acquire resistance to antiviral drugs.

Some researchers are warning, however, that such changes might be more likely to occur not in the northern or southern temperate zones where flu is seasonal, but in the narrow, oftenoverlooked belt of tropical countries where flu circulates all year round.

"We should be getting the message across that it is probably in the tropical countries, more than in the Southern Hemisphere, that this virus will be going through some reassortment contortions in the coming months," says Ken Shortridge, a veteran of flu research in China and southeast Asia, now retired in New Zealand.

Outbreaks of the new virus have so far been largely confined to the Northern Hemisphere, and public-health officials are crossing their fingers that as summer approaches outbreaks may wane - although that is far from a given. That would buy time for a new vaccine to become available just before the expected wave of new cases next winter.

European Union countries have so far succeeded in holding the virus at bay by intensively tracking the first cases imported from abroad, and treating those patients and their contacts with antiviral drugs. Many lowincome countries in the south will not have the resources for such a strategy, says Jeremy Farrar, director of the Oxford University Clinical Research Unit in Ho Chi Minh City, Vietnam. "This inevitably means that when this highly transmissible virus arrives in a densely populated country with more limited resources, it will spread rapidly and many, many thousands of people will be infected," he says.

Scientists have been frustrated by their inability to predict the behaviour of flu viruses, although they are more prepared now for a pandemic than ever before. When the last flu pandemic occurred, in 1968, researchers did not have the web or the molecular-biological and genomic tools to track the disease. "It's the first time in history that we have been able to watch a potentially pandemic virus unfold in advance of a pandemic," says Shortridge. "This is a magnificent advance, but we are still feeling our way."

Jimmy Smith, a member of the World Bank's global H1N1 and H5N1 flu task force in Washington DC, says there are three immediate priorities: "Surveillance, surveillance and surveillance." That includes not only detailed epidemiological analysis of human cases and their clinical spectrum and age profiles, but also more detailed monitoring of animal flu viruses, in particular in pigs and poultry. Intensive surveillance of cases will need to be sustained for at least two years before any conclusions can be drawn as to the severity of the virus, says Keiji Fukuda, acting assistant director-general of the World Health Organization's (WHO's) Health Security and Environment division. "Pandemics do not occur in a couple of days," he says.

In the tropics and the Southern Hemisphere, the infrastructure for surveillance capacity in low-income countries has improved greatly over the past five years because of the need to deal with the threat of H5N1 avian influenza, including expanding the WHO's Global Influenza Surveillance Network. But progress has been slow, and there is still insufficient capacity in many countries, particularly in rural Asia and
Africa. The World Bank is in the process of ramping up funding for flu surveillance for Mexico and any other countries that request it, says Smith.

Surveillance is not just academic; it is key to getting early warnings of events that call for swift adaptations of control strategies. Swine flu is currently sensitive to the antiviral drug oseltamivir (Tamiflu), for example, but seasonal H1N1 is resistant. Were the new virus to acquire resistance, that would render redundant the Tamiflu stockpiled by many nations as part of their pandemic plans.

Tropical countries may be pivotal in such changes. "Tropical zones are the black box of influenza," says Antoine Flahault, dean of
Influenza outside the developed countries of the Northern Hemisphere is often overlooked.

the French School of Public Health in Rennes and Paris. Tropical southeast Asian countries in particular are a hotbed of flu viruses, ranging from H9N2 in children in Hong Kong and China, to H6N1 in birds and, by far the most prevalent, H4N6 in ducks and other waterbirds. The threat of reassortments occurring in poor tropical countries is compounded by the fact that humans tend to live in close proximity with livestock. "If it reassorts, who knows what could result," says Shortridge.

\section{Change in focus}

In a 1988 workshop, Shortridge, along with Alan Kendal, then director of influenza at the US Centers for Disease Control and Prevention in Atlanta, Georgia, first drew attention to the tropics as likely to be the main reservoir for the mixing of flu viruses. Nonetheless, the tropics are largely relegated to an afterthought in textbooks and papers about flu, with most attention being given to seasonal flu in the temperate regions, where most flu researchers work. "Articles about flu in the tropics tend to get glossed over," says Shortridge.

Two flu genome papers ${ }^{1,2}$ published last year, however, provide strong genetic evidence for mixing and mutation in the tropics, to yield new future strains. "All the interesting stuff happens in these tropical reservoirs, with the temperate epidemics in both the Northern and Southern Hemispheres being spillovers from that," says Oliver Pybus, an evolutionary geneticist at the University of Oxford, UK, and co-author of one of the papers. 


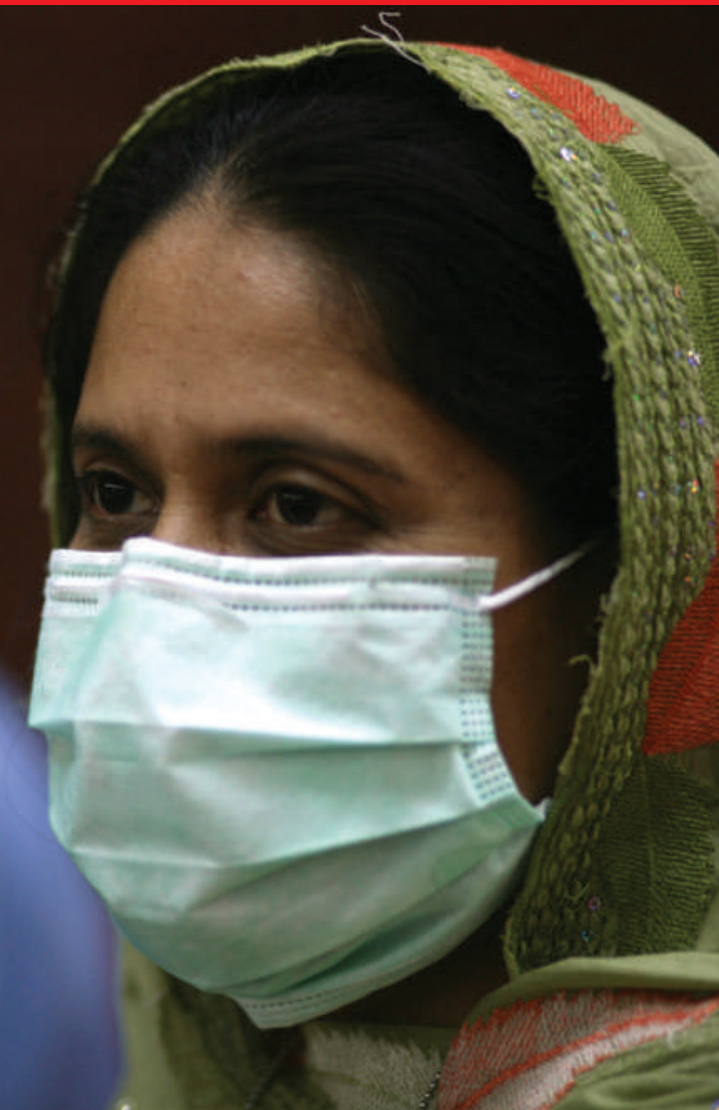

The logical conclusion, he says, is that although surveillance is needed in temperate countries in the Southern Hemisphere during the upcoming flu season, deep sampling of tropical regions would be even more helpful. "But unsurprisingly, surveillance has historically been best in rich countries" that tend to be in temperate latitudes, he says.

On 22 May, Margaret Chan, director-general of the WHO, told the annual meeting of the World Health Assembly - the agency's supreme decision-making body - that nations must unite to help poor countries in the Southern Hemisphere implement control measures. "I strongly urge you to look closely at anything and everything we can do, collectively," she said, " to protect developing countries from, once again, bearing the brunt of a global contagion."

Declan Butler

1. Rambaut, A. et al. Nature $453,615-619$ (2008).

2. Russel, C. A. et al. Science 320, 340-346 (2008).

For Nature's swine flu coverage,

see nature.com/swineflu

\section{HiN1 update}

As confirmed by the World Health

Organization, as of 26 May:

Cases: 12,954, in 46 countries

Deaths: 92 , in 4 countries

AUSTRALIA: Raised the pandemic level to

'Contain' on 22 May, giving authorities the power to close schools.

JAPAN: Urged people not to panic as case numbers reached 350 and spread to Tokyo.

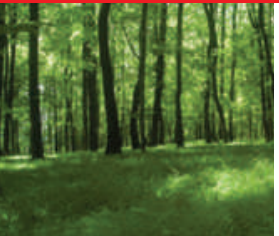

FORESTS AT RISK

International preservation targets will not be met by 2010 .

www.nature.com/news

\section{North Korea's bigger blast}

On the morning of 25 May, when North Korea announced that it had tested a second nuclear device, supporting evidence was already available in the form of waves picked up by seismic stations around the world within minutes. But piecing together what the blast means in terms of the nation's nuclear capacity will take a lot longer.

At 09:55 local time on 25 May, monitors in the Shimane and Tottori prefectures on the Japanese coast picked up seismic waves emanating from the region where North Korea tested a nuclear weapon in 2006 an area with little natural seismic activity. Movements along natural fault lines transmit most of their energy through 's-waves', whereas explosions at a single point release a greater proportion through compressional p-waves. In the waves detected in Japan, the s-wave component was just one-fifth that of the p-wave. "You can't say it's impossible for a natural earthquake, but it would be very rare," says Gen Aoki of the Japan Meteorological Agency in Tokyo.

Japanese officials determined the tremors to be of magnitude 5.3. The US Geological Survey put the strength at 4.7, and the Comprehensive Test Ban Treaty Organization (CTBTO) recorded a magnitude of around 4.5. All three estimates are consistent with a blast equivalent to a few thousand tonnes of TNT.

The yield of North Korea's 2006 test was estimated to be under a kilotonne, and most experts think that it was a 'fizzle' - a detonation in which the nuclear device fails to create a complete chain reaction in its fuel. North Korea's weapons programme uses plutonium, which needs to be compressed with carefully synchronized explosive charges to detonate properly.

Linking the magnitude readings to the explosive power depends on knowledge of the surrounding earth, but the latest test seems to have been around five times the size of the 2006 test, according to Paul Richards, a seismologist at Columbia University in New York. Richards says that the blast was too large to have come from conventional explosives. "To me, a chemical explosion on the order of a few thousand tonnes, with all the stuff detonated at all the same instant, is not a credible scenario," he says.
Martin Kalinowski, a nuclear physicist at the University of Hamburg in Germany, agrees, but says that the test may not have been a complete success. He was expecting a yield of roughly 16 kilotonnes, in line with the first nuclear tests of other nations. Assuming that was the case, then Monday's test "was probably not the yield that North Korea expected", he says.

Others, however, think that North Korea wanted a small blast. In 2006, the nation told the Chinese that its bomb would have a yield of around 4 kilotonnes, according to Andreas Persbo, a senior researcher at

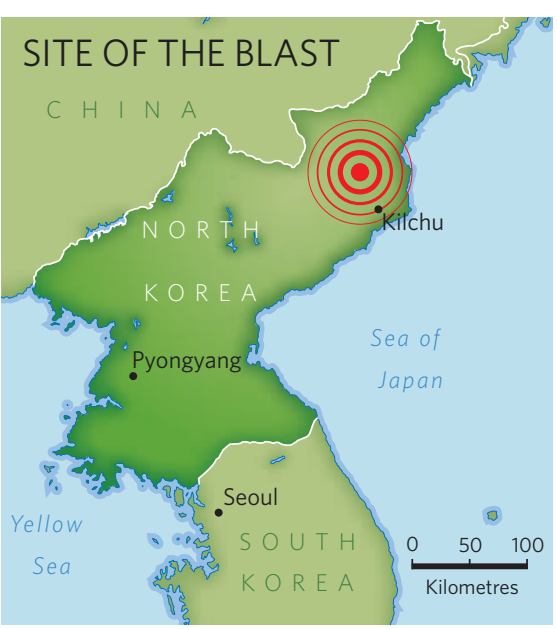

the Verification Research Training and Information Centre (VERTIC) in London. Given the limited amount of nuclear material available to the North Koreans, a small yield might be a sensible choice. "It certainly looks successful to me," he says.

Further confirmation of the nuclear nature of the test is likely to come in the next few weeks. If the underground blast was indeed nuclear, then it will have released radioactive xenon isotopes in ratios that are distinct from those released by other sources, such as nuclear power stations. A representative at Japan's Ministry of Foreign Affairs says that its two radionuclide monitoring stations will not have any results for a couple of days; ground-based CTBTO testing stations in Russia could see the first xenon within the next few days, although it will take weeks to complete the measurements, Kalinowski says. Specially equipped US military aircraft are also likely to be used in the follow up.

Geoff Brumfiel and David Cyranoski 